\title{
Association Between Ordering Patterns and Shift-Based Care in General Pediatrics Inpatients
}

\author{
Neelaysh Vukkadala, $\mathrm{BS}^{1}$, Andrew Auerbach, MD, $\mathrm{MPH}^{2}$, Judith H. Maselli, MPH${ }^{2}$, Glenn Rosenbluth, $\mathrm{MD}^{3 *}$
}

\begin{abstract}
${ }^{1}$ University of California, San Francisco, School of Medicine, San Francisco, California; ${ }^{2}$ Division of Hospital Medicine, University of California, San Francisco, School of Medicine, San Francisco, California; ${ }^{3}$ Division of Pediatric Hospital Medicine, University of California, San Francisco, Benioff Children's Hospital, San Francisco, California.
\end{abstract}

Duty-hour restrictions have forced changes in care models for inpatient services, including an increase in shift work. In this study we aimed to determine whether a shift model compliant with 2011 Accreditation Council for Graduate Medical Education duty-hour standards was associated with more active patient care management. Residents caring for pediatric patients changed from a schedule with extended duty shifts and cross-coverage to one based on day/night shifts, limiting interns to 16 consecutive duty hours. We conducted a retrospective review of orders written under each model. After the intervention, there was a significant increase in the mean number of orders written within the first 12 hours (pre: 0.58 orders vs post: $1.12, P=$ 0.009 ) and 24 hours (pre: 1.52 vs post: $2.38, P=0.004$ ) following admission (not including admission orders), but we did not detect a significantly higher percentage of orders written at night. This shift-based coverage system was associated with a greater number of orders written early in the hospitalization, indicating more active management of clinical problems. Journal of Hospital Medicine 2016;11:210-214. (C) 2015 Society of Hospital Medicine
Duty-hour restrictions were implemented by the Accreditation Council for Graduate Medical Education (ACGME) in 2003 in response to data showing that sleep deprivation was correlated with serious medical errors. ${ }^{1}$ In 2011, the ACGME required more explicit restrictions in the number of hours worked and the maximal shift length. ${ }^{2}$ These requirements have necessitated a transition from a traditional $\mathrm{q} 4$ call model for interns to one in which shifts are limited to a maximum of 16 hours.

Studies of interns working these shorter shifts have had varied results, and comprehensive reviews have failed to demonstrate consistent improvements. ${ }^{3-5}$ Studies of shift-length limitation initially suggested improvements in patient safety (decreased length of stay, ${ }^{6,7}$ cost of hospitalization, ${ }^{6}$ medication errors, ${ }^{7}$ serious medical errors, ${ }^{8}$ and intensive care unit [ICU] admissions $^{9}$ ) and resident quality of life. ${ }^{10}$ However, other recent studies have reported an increased number of self-reported medical errors ${ }^{11}$ and either did not detect change ${ }^{12}$ or reported perceived decreases ${ }^{13}$ in quality of care and continuity of care.

We previously reported decreased length of stay and decreased cost of hospitalization in pediatric inpatients cared for in a day/night-shift-based care model. ${ }^{6}$

*Address for correspondence and reprint requests: Glenn Rosenbluth, MD, Department of Pediatrics, 505 Parnassus Ave, M-691, San Francisco, CA 94143-0110; Telephone: 415-476-9185; Fax: 415-476-4009; E-mail: rosenbluthg@peds.ucsf.edu

Additional Supporting Information may be found in the online version of this article.

Received: November 26, 2014; Revised: September 19, 2015; Accepted: October 15, 2015

2015 Society of Hospital Medicine DOI 10.1002/jhm.2507

Published online in Wiley Online Library (Wileyonlinelibrary.com).
An hypothesized reason for those care improvements is the restructured care model led to increased active clinical management during both day and night hours. Here we report the findings of a retrospective analysis to investigate this hypothesis.

\section{PATIENTS AND METHODS}

\section{Study Population}

We reviewed the charts of pediatric patients admitted to University of California, San Francisco Benioff Children's Hospital, a 175-bed tertiary care facility, over a 2-year period between September 15, 2007 and September 15, 2008 (preintervention) and September 16, 2008 and September 16, 2009 (postintervention). During this study period, our hospital was still dependent on paper orders. Admission order sets were preprinted paper forms that were unchanged for the study period. Using International Classification of Diseases, 9th Revision coding, we identified patients on the general pediatrics service with 1 of 6 common diagnoses-dehydration, community-acquired pneumonia, aspiration pneumonia, upper respiratory infection, asthma, and bronchiolitis. These diagnoses were chosen because it was hypothesized that their length of inpatient stay could be impacted by active clinical management. We excluded patients admitted to the ICU or transferred between services.

A list of medical record numbers (MRNs) corresponding to admissions for 1 of the 6 above diagnoses during the pre- and postintervention periods was compiled. MRNs were randomized and then sequentially reviewed until 50 admissions in each time period were obtained. After data collection was completed, we noted that 2 patients had been in the ICU for part of their hospitalization, and these were excluded, leaving 


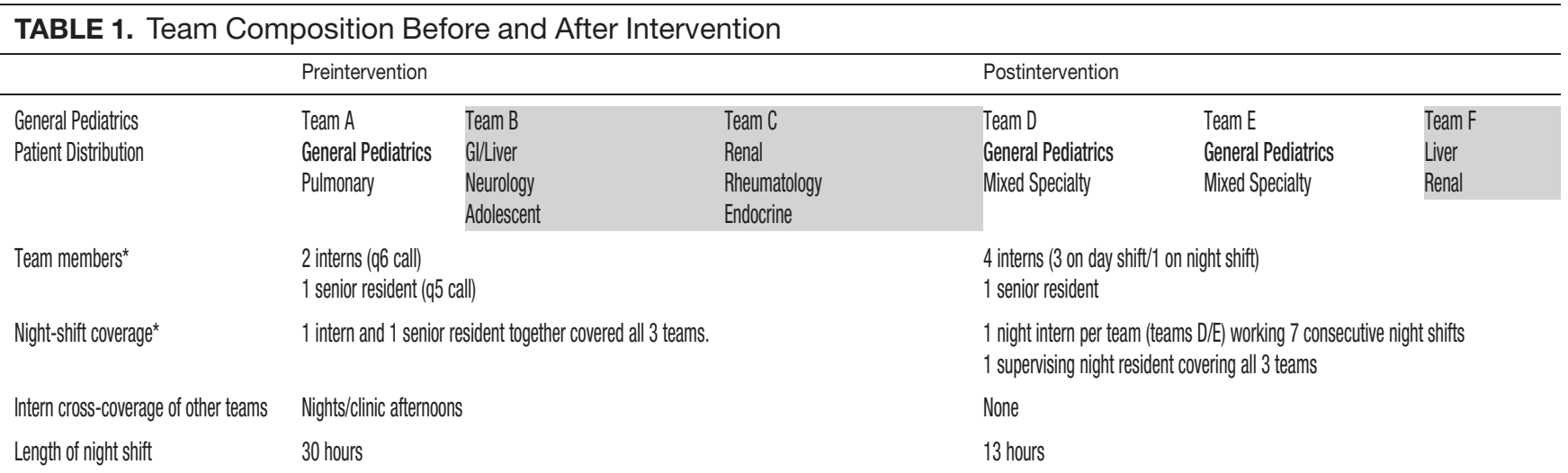

${ }^{*}$ Refers to only to general pediatrics patient coverage - Teams A, D, and E.

NOTE: Abbreviations: Gl, gastrointestinal. *Refers to only to general pediatrics patient coverage-teams A, D, and E.

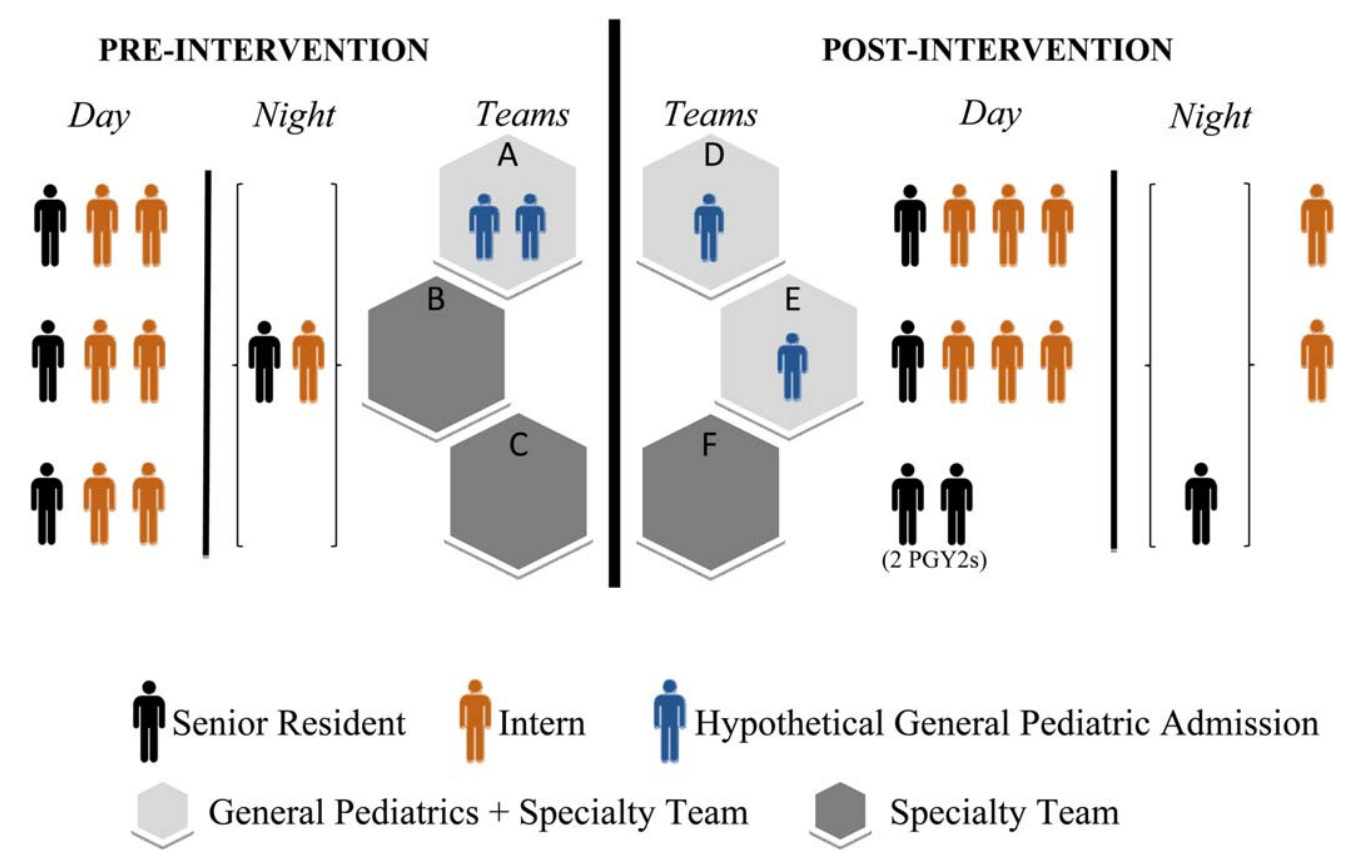

FIG. 1. Team staffing before and after the intervention. Abbreviations: PGY2, postgraduate year 2.

48 admissions from prior to the intervention and 50 admissions from after intervention who were examined.

\section{Intervention}

During the preintervention period, patients were cared for by interns who took call every sixth night (duty periods up to 30 hours), with cross-coverage of patients on multiple teams. Cross-coverage was defined as coverage of patients cared for during nonconsecutive shifts and for whom residents did not participate in attending rounds. Noncall shifts were typically 10 to 11 hours. They were supervised by senior residents who took call every fourth or fifth night and who provided similar cross-coverage.

During the postintervention period, interns worked day and night shifts of 13 hours (1 hour overlap time between shifts for handoffs), with increased night staffing to eliminate intern-level cross-coverage of multiple teams and maintain interns as the primary providers. Interns covered the same team for 5 to 7 consecutive days on either the day or night shifts. Interns remained on the same teams when they switched from day shifts to night shifts to preserve continuity. There were some 24-hour shifts for senior residents on weekends. Senior residents maintained supervisory responsibility for all patients (both hospitalist teams and a subspecialty team). They also worked 7 consecutive nights.

There were changes in the staffing ratios associated with the change to day and night teams (Table 1, Figure 1). In the preintervention period, general pediatrics patients were covered by a single hospitalist and cohorted on a single team (team A), which also covered several groups of subspecialty patients with subspecialty attendings. The team consisted of 2 interns 


\begin{tabular}{|c|c|c|c|}
\hline & $\begin{array}{c}\text { Preintervention, } \\
n=48, N(\%)\end{array}$ & $\begin{array}{l}\text { Postintervention, } \\
n=50, N(\%)\end{array}$ & $P$ Value \\
\hline Age, y, mean (SD) & $4.8(4.6)$ & $5.5(4.7)$ & 0.4474 \\
\hline Race/ethnicity & & & 0.1953 \\
\hline NH white & $12(25.0 \%)$ & $9(18.0 \%)$ & \\
\hline NH black & $11(22.9 \%)$ & $7(14.0 \%)$ & \\
\hline Hispanic & $16(33.3 \%)$ & $13(26.0 \%)$ & \\
\hline Asian & $6(12.5 \%)$ & $10(20.0 \%)$ & \\
\hline Other & $3(6.3 \%)$ & $10(20.0 \%)$ & \\
\hline Missing & 0 & $1(2.0 \%)$ & \\
\hline Gender & & & 0.6577 \\
\hline Female & $19(39.6 \%)$ & $22(44.0 \%)$ & \\
\hline Male & $29(60.4 \%)$ & $28(56.0 \%)$ & \\
\hline Primary language & & & 0.2601 \\
\hline English & $38(79.2 \%)$ & $45(90.0 \%)$ & \\
\hline Spanish & $9(18.8 \%)$ & $5(10.0 \%)$ & \\
\hline Other & $1(2.1 \%)$ & 0 & \\
\hline Insurance & & & 0.0118 \\
\hline Private & $13(27.1 \%)$ & $26(52.0 \%)$ & \\
\hline Medical & $35(72.9 \%)$ & $24(48.0 \%)$ & \\
\hline Other & 0 & 0 & \\
\hline Admit source & & & 0.6581 \\
\hline Referral & $20(41.7 \%)$ & $18(36.0 \%)$ & \\
\hline ED & $26(54.2 \%)$ & $31(62.0 \%)$ & \\
\hline Transfer & $2(4.2 \%)$ & $1(2.0 \%)$ & \\
\hline Severity of illness & & & 0.1926 \\
\hline Minor & $15(31.3 \%)$ & $24(48.0 \%)$ & \\
\hline Moderate & $23(47.9 \%)$ & $16(32.0 \%)$ & \\
\hline Severe & $10(20.8 \%)$ & $10(20.0 \%)$ & \\
\hline Extreme & 0 & 0 & \\
\hline Diagnoses & & & 0.562 \\
\hline Asthma & 21 & 19 & \\
\hline Bronchiolitis & 2 & 4 & \\
\hline Pneumonia & 17 & 19 & \\
\hline Dehydration & 6 & 7 & \\
\hline URI & 0 & 1 & \\
\hline Aspiration pneumonia & 2 & 0 & \\
\hline
\end{tabular}

NOTE: Abbreviations: ED, emergency department; NH, non-Hispanic; SD, standard deviation; URI, upper respiratory infection.

and 1 senior resident, who shared extended (30-hour) call in a cycle with 2 other inpatient teams. In the postintervention period, general pediatrics patients were split between 2 teams (teams D and E) and mixed with subspecialty patients. Hospitalist continued to be the attendings, and these hospitalists also covered specialty patients with subspecialists in consulting roles. The teams consisted of 3 interns on the day shift, and 1 on the night shift. There was 1 senior resident per team on day shift, and a single senior resident covering all teams at night.

There was no change in the paper-order system, the electronic health record, timing of the morning blood draw, use of new facilities for patient care, or protocol for emergency department admission. Concomitant with the restructuring, most subspecialty patients were consolidated onto the hospitalist service, necessitating creation of a second hospitalist team. However, patients admitted with the diagnoses identified above would have been on the hospitalist service before and after the restructuring.
TABLE 3. Distribution of Orders

\begin{tabular}{lccc}
\hline & $\begin{array}{c}\text { Preintervention, } \\
\text { 48 Admissions }\end{array}$ & $\begin{array}{c}\text { Postintervention, } \\
50 \text { Admissions }\end{array}$ & $\begin{array}{c}P \\
\text { Value }\end{array}$ \\
\hline Total no. of orders & 212 & 231 & \\
Mean no. of orders per admission & 4.42 & 4.62 & \\
Day shift orders, $n(\%)$ & $155(73)$ & $155(67)$ & 0.149 \\
Night shift orders, $n(\%)$ & $57(27)$ & $76(33)$ & \\
Mean no. of orders within first 12 hours* & 0.58 & 1.12 & 0.009 \\
Mean no. of orders within first 24 hours* & 1.52 & 2.38 & 0.004 \\
Night shift escalation orders (\%) & $27(47)$ & $33(43)$ & \\
Night shitt de-escalation orders (\%) & $30(53)$ & $43(57)$ & 0.491 \\
\hline
\end{tabular}

NOTE: *Excludes admission order set.

\section{Data Collection/Analysis}

We reviewed specific classes of orders and categorized by type: respiratory medication, oxygen, intravenous (IV) fluids, diet, monitoring, and activity, time of day (day vs night-shift), and whether they were an escalation or de-escalation of care. De-escalation of care was defined as orders that decreased patient care such as weaning a patient off nebulized albuterol or decreasing their IV fluids. Orders between 07:00 to 18:00 were considered day-shift orders and between 18:01 and 06:59 were classified as night-shift orders. Only orders falling into 1 of the aforementioned categories were recorded. Admission order sets were not included. Initially, charts were reviewed by both investigators together; after comparing results for 10 charts to ensure consistency of methodology and criteria, the remaining charts were reviewed by 1 of the study investigators.

To compare demographics, diagnoses, and ordering patterns, $t$ tests and $\chi^{2}$ (SAS version 9.2 [SAS Institute, Cary, NC], Stata version 13.1 [StataCorp, College Station, TX]) were used. Multivariate gamma models (SAS version 9.2 [SAS Institute]) that adjusted for clustering at the attending level and patient age were used to compare severity of illness before and after the intervention. This study was approved by the University of California, San Francisco Committee on Human Research.

\section{RESULTS}

We analyzed data for 48 admissions preintervention and 50 postintervention. With the exception of insurance type, there was no difference in baseline demographics, diagnoses, or severity of illness between the groups (Table 2). Within the order classes above, we identified 212 orders preintervention and 231 orders postintervention.

After the intervention, there was a statistically significant increase in the average number of orders written within the first 12 hours (pre: 0.58 orders vs post: $1.12, P=0.009$ ) and 24 hours (pre: 1.52 vs post: 2.38, $P=0.004$ ) following admission (Table 3), not including the admission order set. The fraction of orders written at night was not significantly different 
(27\% at night preintervention, 33\% postintervention, $P=0.149)$. The fraction of admissions on the day shift compared to the night shift did not change $(P=$ 0.72). There was no difference in the ratio of deescalation to escalation orders written during the night (Table 2).

\section{DISCUSSION}

In this study, we demonstrate increased patient care management early in the hospitalization, measured in this study by the mean number of orders written per patient in the first 12 and 24 hours after admission, after transition from a call schedule with extended ( $>16$ hours) shifts to one with shorter shifts compliant with current ACGME duty-hour restrictions and an explicit focus on greater continuity of care. We did not detect a change in the proportion of total orders written on the night shift compared to the day shift. Earlier active medical management, such as weaning nebulized albuterol or supplemental oxygen, can speed the time to discharge. ${ }^{14}$

Our failure to detect a significant change in the proportion or type of orders written at night may have been due to our small sample size. Anecdotally, after the intervention, medical students reported to us that they noticed a difference between our service, in which we expect night teams to advance care, and other services at our institution, in which nights are a time to focus on "putting out fires." This was not something that had been reported to us prior. It is likely reflective of the overall approach to patient care taken by residents working a night shift as part of a longitudinal care team.

This study builds on previous findings that demonstrated lower costs and shorter length of stay after implementing a schedule based on day and night teams. ${ }^{7}$ The reasons for such improvements are likely multifactorial. In our model, which was purposefully designed to create night-team continuity and minimize cross-coverage, it is likely that residents also felt a greater sense of responsibility for and familiarity with the patients ${ }^{15}$ and therefore felt more comfortable advancing care. Not only were interns likely better rested, the patient-to-provider ratio was also lower than in the preintervention model. Increases in staffing are often necessary to eliminate cross-coverage while maintaining safe, 24-hour care. These findings suggest that increases in cost from additional staffing may be at least partially offset by more active patient management early in the hospitalization, which has the potential to lead to shorter hospital stays.

There are several limitations to our research. We studied a small sample, including a subset of general pediatrics diagnoses that are amenable to active management, limiting generalizability. We did not calculate a physician-to-patient ratio because this was not possible with the retrospective data we collected. Staffing ratios likely improved, and we consider that part of the overall improvements in staffing that may have contributed to the observed changes in ordering patterns. Although intern-level cross-coverage was eliminated, the senior resident continued to cover multiple teams overnight. This senior covered the same 3 teams for 7 consecutive nights. The addition of a hospitalist team, with subspecialists being placed in consultant roles, may have contributed to the increase in active management, though our study population did not include subspecialty patients. There was a difference in insurance status between the 2 groups. This was unlikely to affect resident physician practices as insurance information is not routinely discussed in the course of patient care. In the context of the ongoing debate about duty-hour restrictions, it will be important for future studies to elucidate whether sleep or other variables are the primary contributors to this finding. Our data are derived solely from 1 inpatient service at a single academic medical center; however, we do feel there are lessons that may be applied to other settings.

\section{CONCLUSION}

A coverage system with improved nighttime resident coverage was associated with a greater number of orders written early in the hospitalization, suggesting more active management of clinical problems to advance care.

\section{Acknowledgements}

The authors thank Dr. I. Elaine Allen, John Kornak, and Dr. Derek Pappas for assistance with biostatistics, and Dr. Diana Bojorquez and Dr. Derek Pappas for assistance with review of the manuscript and creation of the figures.

Disclosures: None of the authors have financial relationships or other conflicts of interest to disclose. No external funding was secured for this study. Dr. Auerbach was supported by grant K24HL098372 during the course of this study. This project was supported by the National Center for Advancing Translational Sciences, National Institutes of Health $(\mathrm{NIH})$, through University of California San Francisco-Clinical and Translational Sciences Institute grant UL1 TR000004. Its contents are solely the responsibility of the authors and do not necessarily represent the official views of the NIH. Dr. Rosenbluth had access to all of the data in the study and takes responsibility for the integrity of the data and the accuracy of the data analysis.

\section{References}

1. Philibert I, Friedmann P, Williams WT. New requirements for resident duty hours. JAMA. 2002;288(9):1112-1114.

2. Accreditation Council for Graduate Medical Education. Common program requirements. 2011. Available at: http://www.acgme.org/acgme web/Portals/0/PDFs/Common_Program_Requirements_07012011[2]. pdf. Accessed November 28, 2011.

3. Fletcher KE, Reed DA, Arora VM. Patient safety, resident education and resident well-being following implementation of the 2003 ACGME duty hour rules. J Gen Intern Med. 2011;26(8):907-919.

4. Ahmed N, Devitt KS, Keshet I, et al. A systematic review of the effects of resident duty hour restrictions in surgery: impact on resident wellness, training, and patient outcomes. Ann Surg. 2014;259(6):10411053.

5. Philibert I, Nasca T, Brigham T, Shapiro J. Duty-hour limits and patient care and resident outcomes: can high-quality studies offer insight into complex relationships? Annu Rev Med. 2013;64:467483 .

6. Rosenbluth G, Fiore DM, Maselli JH, Vittinghoff E, Wilson SD, Auerbach AD. Association between adaptations to ACGME duty hour requirements, length of stay, and costs. Sleep. 2013;36(2):245248. 
7. Gottlieb DJ, Parenti CM, Peterson CA, Lofgren RP. Effect of a change in house staff work schedule on resource utilization and patient care. Arch Intern Med. 1991;151(10):2065-2070.

8. Landrigan CP, Rothschild JM, Cronin JW, et al. Effect of reducing interns' work hours on serious medical errors in intensive care units. N Engl J Med. 2004;351(18):1838-1848.

9. Horwitz LI, Kosiborod M, Lin Z, Krumholz HM. Changes in outcomes for internal medicine inpatients after work-hour regulations. Ann Intern Med. 2007;147(2):97-103.

10. Levine AC, Adusumilli J, Landrigan CP. Effects of reducing or eliminating resident work shifts over 16 hours: a systematic review. Sleep. 2010;33(8):1043-1053.

11. Sen S, Kranzler HR, Didwania AK, et al. Effects of the 2011 duty hour reforms on interns and their patients: a prospective longitudinal cohort study. JAMA Intern Med. 2013;173(8):657-662; discussion 663.

12. McCoy CP, Halvorsen AJ, Loftus CG, McDonald FS, Oxentenko AS. Effect of 16-hour duty periods on patient care and resident education. Mayo Clin Proc. 2011;86(3):192-196.

13. Desai SV, Feldman L, Brown L, et al. Effect of the 2011 vs 2003 duty hour regulation-compliant models on sleep duration, trainee education, and continuity of patient care among internal medicine house staff: a randomized trial. JAMA Intern Med. 2013;173(8):649-655.

14. Johnson KB, Blaisdell CJ, Walker A, Eggleston P. Effectiveness of a clinical pathway for inpatient asthma management. Pediatrics. 2000; 106(5):1006-1012.

15. Burgis JC, Lockspeiser TM, Stumpf EC, Wilson SD. Resident perceptions of autonomy in a complex tertiary care environment improve when supervised by hospitalists. Hosp Pediatr. 2012;2(4):228-234. 